\title{
Commentaries
}

\section{COX-2 in large bowel cancer: a one-sided story}

Colorectal cancer is the third most common cancer and the second most common cause of death from cancer in many industrialised countries. This disease will affect 5\% of the US population, resulting in over 130000 new cases and 57000 deaths projected this year. The age adjusted death rates are highly variable in populations located in different parts of the world. For example, there are 3.4 cases per 100000 in Nigeria compared with 35.8 cases per 100000 each year in the state of Connecticut, USA. This indicates that, apart from the known genetic factors, certain environmental and dietary factors are probably involved in the aetiology of this disease. Epidemiological, clinical and genetic evidence indicates that a great number of colorectal adenocarcinomas develop from a benign adenomatous polyp progressing through a sequence of events which may take about 15-20 years. ${ }^{1}$ The progression of events leading to transformation of colonic epithelial cells includes a series of mutations in key genes which affect regulation of cell growth, cellular differentiation, DNA repair, apoptosis, and other biological processes. $^{2}$

Some patients inherit a clear genetic predisposition to colorectal cancer and have been grouped into either polyposis or non-polyposis syndromes based on the phenotype they exhibit. ${ }^{3}$ Patients with familial adenomatous polyposis (FAP) typically develop hundreds to thousands of colonic polyps at an early age and possess a germline mutation in their adenomatous polyposis coli (APC) gene. Patients with hereditary non-polyposis colorectal cancer (HNPCC) typically have very few polyps and often develop carcinomas on the right side of the colon at an early age. Patients with HNPCC usually inherit a germline mutation in one of a set of genes required to repair mismatched bases in DNA. ${ }^{4}$

Patients with FAP have been of particular interest for studies designed to evaluate agents for their ability to induce polyp regression. Non-steroidal anti-inflammatory drugs (NSAIDs) have been evaluated in this patient population and results from clinical trials have shown that use of these drugs leads to a significant reduction in polyp size and number. ${ }^{5}$ Additionally, epidemiological studies have revealed that use of NSAIDs in the general population leads to a $40-50 \%$ reduction in the risk of developing colorectal cancer. ${ }^{6-10}$ These clinical studies have led researchers to evaluate potential mechanisms whereby NSAIDs could reduce the risk of developing colorectal cancer and induce polyp regression. One property shared by all NSAIDs is their ability to inhibit prostaglandin synthesis by inhibiting the activity of cyclooxygenase (COX) enzymes. Two COX isoforms have been identified, referred to as COX-1 and COX-2 as a result of the temporal order in which they were discovered. ${ }^{11} \mathrm{COX}-1$ is produced constitutively in many circumstances. However, COX-2 is induced at sites of inflammation and its synthesis is stimulated by a number of cytokines, growth factors and tumour promoters. ${ }^{12}{ }^{13}$ Most NSAIDs currently available for clinical use inhibit both COX-1 and COX-2. Recently, a new class of NSAID has been developed comprising highly selective inhibitors of COX-2 and which seem to have greatly improved gastrointestinal safety profiles. ${ }^{14}{ }^{15}$ Selective COX-2 inhibitors have been shown to be effective at preventing intestinal tumour formation and inhibiting colon carcinoma growth in animal models of intestinal tumorigenesis. ${ }^{16-18}$ Therefore, there is considerable interest in the potential role of COX-2 in the pathogenesis of colorectal cancer.

The relative levels of COX-2 and COX-1 expression in colorectal cancers have been evaluated by a number of different groups which have reported increased expression in colorectal carcinomas. ${ }^{19-21}$ Published reports indicate that roughly $85 \%$ of adenocarcinomas exhibit a $2-50$-fold increase in COX-2 expression compared with the adjacent normal mucosa. ${ }^{19}$ However, in the previous studies no attempt was made to compare the amount of COX-2 expression with the colonic location of the lesion. Dimberg et al (see page 730) report here for the first time that COX-2 is differentially expressed in colorectal cancers found in various regions of the colon. They found that COX-2 protein was greatly overexpressed in tumours located in the rectum compared with other regions of the colon. Interestingly, no association between increased COX-2 expression in tumour tissue and Dukes' stage was found. These results highlight the need for future studies aimed at determining the precise location of COX-2 expression within tumours and the reason for the predominance of high expression in rectal carcinomas. More importantly, we need to answer the question whether these results portend a clinical outcome or predict any clinical significance with regard to treatment options.

R N DuBOIS

Department of Medicine/GI,

Medical Centre North C-2104,

116121 st Avenue South,

Vanderbilt University Medical Centre,

Nashville, TN 37232-2279, USA

1 Winawer SJ, Zauber AG, Gerdes H, et al. Risk of colorectal cancer in the families of patients with adenomatous polyps. National Polyp Study Workgroup. N Engl F Med 1996;334:1339-40.

2 Kinzler KW, Vogelstein B. Landscaping the cancer terrain. Science 1998;280:1036-7.

3 Kinzler KW, Vogelstein B. Lessons from hereditary colorectal cancer. Cell 1996;87:159-70.

4 Boland CR. Roles of the DNA mismatch repair genes in colorectal tumorigenesis. Int f Cancer 1996;69:47-9.

5 Giardiello FM, Offerhaus GJA, DuBois RN. The role of nonsteroidal antiinflammatory drugs in colorectal cancer prevention. Eur $\mathcal{F}$ Cancer 1995;31A:1071-6.

6 Thun MJ, Namboodiri MM, Heath CWJ. Aspirin use and reduced risk of fatal colon cancer. $N$ Engl F Med 1991;325:1593-6.

7 Thun MJ, Namboodiri MM. Calle EE, et al. Aspirin use and risk of fatal cancer. Cancer Res 1993;53:1322-7.

8 Giovannucci E, Rimm EB, Stampfer MJ, et al. Aspirin use and the risk of colorectal cancer and adenoma in male health professionals. Ann Intern Med 1994;121:241-6.

9 Giovannucci E, Egan KM, Hunter DJ, et al. Aspirin and the risk of colorectal cancer in women. N Engl F Med 1995;333:609-14.

10 Smalley W, Ray WA, Daugherty J, et al. Use of nonsteroidal antiinflammatory drugs and incidence of colorectal cancer: a population-based study. Arch Int Med 1999;159:161-9.

11 Williams CW, DuBois RN. Prostaglandin endoperoxidase synthase: why two isoforms? Am f Physiol 1996;270:G393-400.

12 DuBois EN, Awad J, Morrow J, et al. Regulation of eicosanoid production and mitogenesis in rat intestinal epithelial cells by transforming growth factor- $\alpha$ and phorbol ester. $\mathcal{7}$ Clin Invest 1994;93:493-8.

13 DuBois RN, Tsujii M, Bishop P, et al. Cloning and characterization of a growth factor-inducible cyclooxygenase gene from rat intestinal epithelial growth factor-inducible cyclooxygenase
cells. Am f Physiol 1994;266:G822-7.

14 Laine L, Hawkey C, Harper S, et al. Effect of the COX-2 specific inhibitor (C-2SI) Rofecoxib on ulcer formation: a double-blind comparison with ibuprofen and placebo [abstract]. Gastroenterology 1999;116:G0996. 
15 Goldstein JL, Agrawal NM, Silverstein F, et al. Celecoxib is associated with a significantly lower incidence of clinically significant upper gastrointestinal (UGI) events in osteoarthritis and rheumatoid arthritis patients compared to NSAIDs [abstract]. Gastroenterology 1999;116:G0758.

16 Sheng H, Shao J, Kirkland SC, et al. Inhibition of human colon cancer cell growth by selective inhibition of cyclooxygenase-2. 7 Clin Invest 1997;99:2254-9.

17 Oshima M, Dinchuk JE, Kargman SL, et al. Suppression of intestinal polyposis in APC ${ }^{\Delta 716}$ knockout mice by inhibition of prostaglandin endoperoxidase synthase-2 (COX-2). Cell 1996;87:803-9.
18 Kawamori T, Rao CV, Seibert K, et al. Chemopreventive activity of celecoxib, a specific cyclooxygenase-2 inhibitor, against colon carcinogencelecoxib, a specific cyclooxygen

19 Eberhart CE, Coffey RJ, Radhika A, et al. Up-regulation of cyclooxygenase-2 gene expression in human colorectal adenomas and adenocarcinomas. Gastroenterology 1994;107:1183-8.

20 Kargman S, O’Neill G, Vickers P, et al. Expression of prostaglandin G/H synthase-1 and -2 protein in human colon cancer. Cancer Res 1995;55:2556-9.

21 Sano H, Kawahito Y, Wilder RL, et al. Expression of cyclooxygenase-1 and -2 in human colon cancer. Cancer Res 1995;55:3785-9.

\section{Are dilating bile ducts a cause for concern?}

Whether the bile duct dilates after cholecystectomy is a hoary old chestnut dating back to Oddi and hotly debated in the era of intravenous cholangiography but is still of practical importance now. In this issue Majeed et al (see page 741) report a careful, but uncontrolled study from Sheffield examining this question. Fifty nine patients undergoing cholecystectomy had their common hepatic duct diameters measured ultrasonographically before and three, six, 12, and 60 months after surgery. Those with ducts of $>5 \mathrm{~mm}$ preoperatively were excluded. A slight mean increase was found and more importantly, perhaps, about $5 \%$ of subjects at six months and one year had ducts greater than the arbitrary cut off limit of $6 \mathrm{~mm}$. At five years only one of the 48 at risk seemed to maintain the increase in size. One wonders whether the radiologist's technique and interpretation at five years were identical to those at the outset. Furthermore, by the end of the study the ultrasound machine was at least nine years old. One assumes that image quality remained sufficiently good for the purpose throughout this period. The lack of a control group leaves these questions open.

The authors report the error of the method as being around $1 \mathrm{~mm}$ as most ultrasound machines measure in increments of whole millimetres, and therefore discount an increase in size of $15.2 \%$ at one year. It is, however, unlikely that the error should be systematically in the same direction. In addition, it is known that the bile duct diameter increases with age, estimates ranging from $0.3 \mathrm{~mm}$ per decade to more than $1 \mathrm{~mm} \cdot{ }^{1-3}$ So on age grounds alone, the ducts should have dilated half this amount over the five years of the study.

This begs two further questions: firstly, what is the importance of this study to patients and, secondly, how does it compare with other studies of the same phenomenon?

Bolton and Le Quesne stated succinctly that, "the demonstration of a dilated duct in a patient who has undergone cholecystectomy is of no immediate significance unless the calibre of duct at the time of operation is known." In clinical practice, a patient with postcholecystectomy pain rarely brings her preoperative ultrasound films or duct diameter measurements with her. The usual problem is a patient with a duct of around $1 \mathrm{~cm}$ in whom neither preoperative duct size nor whether the duct was explored are known. Knowing the current duct size in such an individual is of very little value. Hamilton et $a l^{5}$ who did an endoscopic retrograde cholangiopancreatoraphy (ERCP) study in preand postcholecystectomy patients, further stated that, "methods of evaluating the biliary tract which rely on the measurement of bile duct diameter. . .are. . . of limited value in the investigation of post-cholecystectomy patients."
Majeed and colleagues concede that a number of previous studies have shown "a trend towards a minor degree of duct dilatation." Do these many studies add up to a convincing dataset in favour of postcholecystectomy dilatation? Unfortunately, detailed perusal of previous studies suggests that their quality was often very poor and certainly the methodology was so variable that it is impossible to conduct anything that could be termed a true meta-analysis. Hughes and colleagues ${ }^{6}$ showed no change, whereas Hunt and Scott showed a $12.5 \%$ increase in common hepatic duct diameter in 21 patients examined five years after cholecystectomy. ${ }^{3}$ However, as in all other studies, a mean increase covered a wide range of changes, including several which had decreased in size. Graham et al's ${ }^{7}$ and Mueller et al's ${ }^{8}$ papers are really not of sufficient quality to analyse but did show that only a minority of bile ducts dilate significantly. Hammarstrom's group reported an average $27 \%$ increase in common hepatic duct diameter a mean of 62.8 months postoperatively but they also noted that those with a large increase were older than those whose ducts were normal or did not increase very much. ${ }^{9}$ Gylstorff and Faber's study ${ }^{10}$ is uninterpretable as symptomatic patients were included, some of whom may have had retained stones and although Hamilton et al's study ${ }^{5}$ showed $66 \%$ greater bile duct diameter in post- as opposed to precholecystectomy patients, these were not the same patients and thus were not controls in the same sense as those in other studies.

The facts therefore appear to be these: bile ducts tend to dilate after cholecystectomy but in over $90 \%$ this is minor. A few patients with a more significant dilatation tend to be older and the reasons for this are not known. One cannot therefore assume that in a postcholecystectomy patient a dilated duct is simply the result of the operation and "the reservoir capacity" of the gall bladder being taken over by the duct system.

The final point must be that a patient with convincing postcholecystectomy symptoms, whatever the diameter of the duct, needs high resolution cholangiography, whether ERCP, MRCP, or endoscopic ultrasound. The converse is also true that in an asymptomatic patient whose duct is found incidentally to be dilated, no further investigation is required.

M L WILKINSON

Gastroenterology Laboratory,

GKT 4th Floor, North Wing,

St Thomas's Hospital,

London SE1 7EH, UK

1 Hernanz Schulman M, Ambrosino MM, Freeman PC, et al. Common bile duct in children: sonographic dimensions. Radiology 1995;195:193-5.

2 Barthet M, Spinoza S, Affriat C, et al. Influence of age and biliary lithiasis on the diameter of the common bile duct [in French]. Gastroenterol Clin Biol 1995;19:156-60

3 Hunt DR, Scott AJ. Changes in bile duct diameter after cholecystectomy: a 5-year prospective study. Gastroenterology 1989;97:1485-8.

4 Bolton J, Le Quesne LP. Post-cholecystectomy syndromes. In: Smith R, Sherlock S, eds. Surgery of the gallbladder and bile ducts. 2nd edn. London: Butterworths, 1981:257-311.

5 Hamilton I, Ruddell WS, Mitchell CJ, et al. Endoscopic retrograde cholangiograms of the normal and post-cholecystectomy biliary tree. Br $\mathcal{F}$ Surg 1982;69:343-5.

6 Hughes J, LoCurcio S, Edmunds R, et al. The common duct after cholecystectomy. $\mathscr{F} A M A$ 1966;197:247-50. 
7 Graham MF, Cooperberg PL, Cohen MM, et al. Size of the normal common hepatic duct following cholecystectomy: an ultrasonographic study. Radiolhepatic duct following $1981 ; 35: 137-9$.

Mueller PR, Ferrucci JT, Simeone JF Jr, et al. Observations on the distensibility of the common bile duct. Radiology 1982;142:467-72.
9 Hammarstrom LE, Holmin T, Ebbesen A, et al. Influence of cholecystectomy on bile duct width. Br f Surg 1996;83:1706-8.

10 Gylstorff $\mathrm{H}$, Faber $\mathrm{H}$. Choledochus changes after cholecystectomy (pre- and postoperative examination of 400 patients). Acta Chir Scand 1963;125: postopera 01 .

\section{T-cell lymphoma: the real thing}

It is altogether appropriate that the gut should possess efficient immunological defences given the interface between its antigen-rich contents and the permeable mucosa. More than that, however, the gut is an important immunological organ in its own right. In this respect, the gut mucosa contains more lymphocytes than all other organs of the immune system combined. It is estimated that in humans a metre of intestine contains $10^{10}$ lymphocytes, which is almost equivalent to the number contained in the spleen. ${ }^{1}$ In the light of this quantitative difference and the fact that intestinal lymphoid tissues are subject to constant immunostimulation, it might be expected that a larger proportion of lymphomas would arise from the intestine than the peripheral lymphoid system but, curiously, the contrary is true. Although the gastrointestinal tract is the commonest site of extra-nodal lymphoma in Western countries, only $10 \%$ of lymphomas overall arise there. ${ }^{2}$ There are, however, significant differences in the types of lymphoma that arise in the gut compared with the peripheral lymphoid tissues. Thus, both Hodgkin's disease and follicular lymphoma, among the commonest tumours of peripheral lymph nodes, only rarely arise in the gut. Most gastrointestinal lymphomas are gastric B-cell lymphomas of mucosa associated lymphoid tissue (MALT) type that arise from non-native lymphoid tissue acquired by the gastric mucosa usually following Helicobacter pylori infection. ${ }^{3}$ A smaller proportion of B-cell lymphomas arises in the intestine, presumably from native MALT. T-cell lymphomas arising in the intestine, although frequently featured in single case reports, are uncommon ${ }^{4}$ but include at least one specific subtype, namely enteropathy associated T-cell lymphoma, which occurs as a complication of coeliac disease. ${ }^{5}$ In this issue (see page 662), Carbonnel and colleagues describe four patients with low grade T-cell lymphoma characterised by diffuse infiltration of the intestinal mucosa and suggest that these cases comprise a new distinctive clinicopathological entity.

In formulating the revised European American lymphoma (REAL) classification, ${ }^{6}$ which is in the process of evolving into the new World Heath Organization classification, the International Lymphoma Study Group took the view that the classification should consist as far as possible of a list of real disease entities. The criteria by which an "entity" was defined were morphology, phenotype and genotype, normal cell counterpart and clinical features including site of origin. Although all these criteria were taken into account in defining entities, the emphasis was not necessarily the same for each. Some lymphoma entities are consistently homogeneous by all the criteria whereas others although morphologically homogeneous, might not display a reproducible phenotype and not conform to any known normal cell counterpart but be characterised by distinctive clinical features. It was hoped that defining distinctive diseases in this way would lead to greater insight into lymphoma biology and to the eventual development of properly tailored therapies. Although this system works admirably for B-cell lymphomas, it has proved especially difficult to collect the T-cell lymphomas into distinctive entities. With a few exceptions, these relatively rare tumours tend to be morphologically and phenotypically heterogeneous and their genetic features are poorly characterised. Establishing a normal cell counterpart often proves impossible and, equally, their clinical features tend to vary from case to case. Not surprisingly, most T-cell lymphomas, whether nodal or extranodal, including those arising in the intestine, end up being classified under the category "T-cell lymphoma unspecified" in the REAL classification.

Enteropathy associated T-cell lymphoma is one of the exceptions and is the only intestinal T-cell lymphoma that is recognised as a distinct entity in the REAL and WHO classifications. Although morphologically heterogeneous, the lymphoma demonstrates a relation to normal intraepithelial T-lymphocytes (IEL) by virtue of its phenotype, which is similar but not identical to that of the major IEL population, and the tendency of the neoplastic cells to accumulate widely within the intestinal epithelium. ${ }^{7}$ No distinctive genotypic features have been described. The most important defining feature of enteropathy associated T-cell lymphoma is its association with coeliac disease. Have Carbonnel et al now described a second distinctive intestinal T-cell lymphoma? Morphologically, their cases seem to be remarkably homogeneous, their low-grade cytology being unusual for T-cell lymphomas which are more often comprised of pleomorphic medium-sized and large cells. The wide distribution of the tumour cells throughout the lamina propria of the intestinal mucosa is another unusual characteristic. In common with enteropathy associated T-cell lymphoma, this suggests a specific association with native gut lymphoid tissue, in this case the lamina propria rather than the intraepithelial $\mathrm{T}$ cells. The phenotype of the lymphomas, although similar in all cases, is not distinctive but would be in keeping with origin from normal CD4+ positive lamina propria $\mathrm{T}$ cells. Although genotypic abnormalities are described in only two cases, in which they were notably different, studies of more cases may yet reveal homogeneous changes. Finally, the distinctive slow relentless course and prolonged survival manifested by all four patients is unusual for T-cell lymphomas, which are usually clinically aggressive, and suggests a degree of clinical homogeneity.

According to the principles of the REAL and WHO classifications Carbonnel et al would seem to have described a subtype of intestinal T-cell lymphoma that constitutes a reproducible "entity". Their findings will need to be confirmed by further reports of similar cases which, on past experience, will very likely be forthcoming. Any advance that helps to rationalise the heterogeneous assortment of T-cell neoplasms is to be welcomed.

P G ISAACSON

Department of Histopathology,

Royal Free and University College Medical School, London WC1E 67f, UK

1 Brandtzaeg P. Overview of the mucosal immune system. Curr Top Microbiol Immunol 1989;146:13-25.

2 Greiner TC, Medeiros LJ, Jaffe ES. Non-Hodgkin's lymphoma. Cancer 1995;75(suppl):370-80.

3 Isaacson PG. Gastrointestinal lymphomas of T- and B-cell types. Mod Pathol 1999;12:151-8.

4 Chott A, Dragosics B, Radaszkiewicz T. Peripheral T-cell lymphomas of the intestine. Am f Pathol 1992;141:1361-71.

5 Chott A, Vesely M, Simonitsch I, et al. Classification of intestinal T-cell neoplasms and their differential diagnosis. Am f Clin Pathol 1999;111(suppl 1):S68-74. 
6 Harris NL, Jaffe ES, Stein H, et al. A revised European-American classification of lymphoid neoplasms: a proposal from the International classification of lymphoid neoplasms: a proposal
Lymphoma Study Group. Blood 1994;84:1361-92.
7 Bagdi E, Diss TC, Munson P, et al. Mucosal intra-epithelial lymphocytes in enteropathy associated T-cell lymphoma, ulcerative jejunitis and refractory celiac disease constitute a neoplastic population. Blood 1999;94:260-4.

\section{Renal sodium handling in pre-ascitic cirrhosis}

Sodium retention leading to the accumulation of fluid within the abdominal cavity in the form of ascites is the most common renal functional abnormality in advanced decompensated cirrhosis. ${ }^{1}$ The predominant mechanism underlying sodium retention in these patients is increased renal tubular sodium reabsorption secondary to exacerbated activity of the endogenous vasoactive systems and sodium retaining mechanisms. In fact, in cirrhosis and ascites, sodium retention takes place in the setting of a normal or moderately reduced glomerular filtration rate and increased activity of the renin-angiotensin-aldosterone system, one of the most powerful vasoconstrictor systems involved in body fluid homoeostasis. ${ }^{12}$

Whereas in decompensated cirrhosis the mechanism that initiates sodium retention and ascites formation is quite well established, in pre-ascitic cirrhosis it still remains a subject of interest and debate. Patients with compensated cirrhosis (patients without ascites on a normal sodium diet and without diuretics) usually do not exhibit sodium retention. ${ }^{1}$ Moreover, the activity of the renin-angiotensin-aldosterone system, estimated by plasma renin activity and circulating concentrations of aldosterone, is consistently found to be either normal or decreased in pre-ascitic cirrhotic patients. ${ }^{12}$ These patients, however, have subtle abnormalities in renal sodium handling leading to an expanded circulatory blood volume but without causing ascites or oedema. Indeed, the existence of altered renal sodium metabolism in pre-ascitic cirrhotic patients can be uncovered readily by administering a sodium overload or following mineralocorticoid treatment. ${ }^{1}$ Therefore, and although not clinically evident, pre-ascitic cirrhotic patients have a positive sodium balance which presumably is a homoeostatic mechanism to compensate for the reduced effective arterial blood volume as a result of arteriolar vasodilatation.

In this issue (see page 750), Sansoè and coworkers have re-examined circulatory volume status in pre-ascitic cirrhotic patients. To this end, plasma concentrations of active renin and aldosterone and dopaminergic activity were measured in 12 patients with Child-Pugh class A cirrhosis and nine controls on a normal sodium diet. Dopaminergic activity was assessed by the incremental aldosterone responses to the intravenous administration of metoclopramide, a dopamine DA2 receptor antagonist, and relies on the tonic inhibitory effect of endogenous dopamine on adrenal mineralocorticoid secretion. Compared with controls, patients with pre-ascitic cirrhosis had increased dopaminergic activity, which inversely correlated with active renin plasma concentrations. The authors perceived these findings as evidence of an expanded central plasma volume and consequently proposed the assessment of dopaminergic activity as a novel, reliable and useful marker of fluid volume status in cirrhosis.

More importantly, Sansoè et al also investigated the distribution of sodium reabsorption along the segments of the renal tubule in pre-ascitic cirrhotics by means of lithium clearance. The lithium clearance method is a very useful index of fluid delivery to the distal tubule and is based on the assumption that this ion is reabsorbed in the proximal tubule in parallel with sodium and water. This method has been widely used to evaluate intrarenal sodium handling in humans and animals ${ }^{3-5}$ and has been useful in elucidating that the proximal portion of the nephron is the main site of increased sodium reabsorption in cirrhosis with ascites. ${ }^{6}$ However, two main criticisms have been raised against the use of this technique in cirrhosis. Firstly, the reliability of lithium clearance as a marker of distal fluid delivery in clinical conditions characterised by low fractional sodium excretion (below $0.40 \%$ ) has not yet been proved. ${ }^{7}$ Secondly, it is not clear whether lithium transport also occurs beyond the proximal tubule (i.e., Henle's loop) in cirrhosis. ${ }^{8}$ Using the lithium clearance method, Sansoè et al report the existence of increased distal fractional sodium reabsorption in pre-ascitic cirrhotic patients. This conclusion arises from the calculation of distal fractional sodium reabsorption as the result of dividing values of absolute distal sodium reabsorption by those for filtered sodium load. However, and contrary to what was expected and observed in previous investigations, ${ }^{12}$ the pre-ascitic cirrhotic patients had significantly lower values for the glomerular filtration rate and filtered sodium load. Therefore, in these patients the calculated increase in distal fractional sodium reabsorption reflects diminished delivery of fluid to the distal segment rather than increased distal tubular sodium reabsorption. In fact, when the authors calculated distal fractional sodium reabsorption as a function of absolute distal sodium reabsorption divided by absolute distal sodium delivery, no differences were obtained for tubular sodium handling between cirrhotic and control groups. Whether similar values in glomerular filtration rate would be obtained by estimating this parameter with more sensitive clearance techniques, such as inulin clearance, is not known. Taken together and although further studies are needed to characterise fully intrarenal sodium handling in pre-ascitic cirrhotic patients, Sansoè et al's paper does bring to our attention the notion that central fluid volume derangements and renal tubular sodium avidity are unequivocally two critical events in compensated cirrhosis.

J CLÀRIA

J RODÉS

Liver Unit,

Institut d'Investigacions Biomèdiques August Pi i Sunyer (IDIBAPS),

Hospital Clinic,

Universitat de Barcelona,

Spain

1 Ginés P, Rodés J. Clinical disorders of renal function in cirrhosis with ascites. In: Arroyo V, Schrier RW, Rodés J, Ginés P, eds. Ascites and renal dysfunction in: Arroyo V, Schrier RW, Rodes J, Gines P, eds. Ascites and renal dysfunction in hiver disease. Pathogenes

2 Arroyo V, Planas R, Gaya J, et al. Sympathetic nervous activity, renin-angiotensin system and renal excretion of prostaglandin E2 in cirrhosis. Relationship to functional renal failure and sodium and water excretion. Eur f Clin Invest 1983;13:271-8.

3 Thomsen K. Lithium clearance: a new method for determining proximal and distal tubular reabsorption of sodium and water. Nephron 1984;37: $217-23$.

4 Koomans HA, Boer WH, Dorthout Mees EJ. Evaluation of lithium clearance as a marker of proximal tubule sodium handling. Kidney Int 1989;36:2-12.

5 Clària J, Jiménez W, LaVilla G, et al. Effects of endothelin on renal hemodynamics and segmental sodium handling in conscious rats. Acta Physiol Scand 1991;141:305-8.

6 Anegli P, Gatta A, Caregaro L, et al. Tubular site of renal sodium retention in ascitic liver cirrhosis evaluated by lithium clearance. Eur $\mathcal{F}$ Clin Invest 1990;20:111-17.

7 Kirchner KA. Lithium as a marker for proximal tubular delivery during low salt intake and diuretic infusion. Am f Physiol 1987;252:F188-96.

8 Angeli P, De Bei E, Dalla Pria M, et al. Effects of amiloride on renal lithium handling in nonazotemic ascitic cirrhotic patients with avid sodium retention. Hepatology 1992;15:651-4. 